\title{
The Acquisition of the Third Person Singular [-s]: A Case Study of Language-minority Children Attending an Irish Primary School
}

\author{
Niamh Kelly ${ }^{1}$ \\ ${ }^{1}$ Dublin City University, Ireland \\ Correspondence: Niamh Kelly, Dublin City University, Ireland
}

Received: September 2, 2016

Accepted: November 29, 2016

Online Published: January 13, 2017

doi:10.5430/elr.v6n1p1

URL: http://dx.doi.org/10.5430/elr.v6n1p1

\begin{abstract}
This study investigates the development of the third-person singular (3SG)[-s] morpheme in the spontaneous speech of five language minority children attending an Irish primary school, where the language of instruction is the second language (L2) of the subjects. Evidence from the study is discussed in the context of a number of theories which have been put forward in the literature to account for the development of the 3SG. Results support some of the predictions of the Optional Infinitive Theory, and would argue in favour of the Missing Surface Inflection Hypothesis. The parallel use of both finite and non-finite verbs in obligatory finite contexts is explored, and while the sporadic omission of the 3SG morpheme is similar to the sporadic omission of the genitive [-s] morpheme, the use of objective case marking ceasing in verbal projections yet continuing in nominal projections, questions the extent to which a parallel occurs between possessive and 3SG inflections.
\end{abstract}

Keywords: Child language acquisition, Language-minority children, Morpheme order, Third person singular, Genitive marker

\section{Introduction}

In English, verbs marked with third person singular subjects are generally inflected with the morphological marker [-s], commonly referred to as a verbal agreement or number concord marker (Johnson, de Villiers and Seymour, 2005). Although the third person [-s] morpheme is often referred to as the present tense morpheme, whether or not the morpheme does carry tense at all has been argued in the literature, with Bobaljik (2001) and Enç (1990), cited in Johnson, de Villiers and Seymour (2005) and Sauerland (2002) arguing that the present tense is more frequently marked by the present progressive [-ing], with the [-s] morpheme marking generic aspect. However, regardless of whether it is considered a carrier of tense or not, there is agreement that since [-s] only marks the third person singular of a verbal form and does not mark any other subject, it does indicate both number and person.

Although early morpheme studies on L1 acquisition carried out by Brown (1973) and de Villiers and de Villiers (1973) found that the third person [-s] morpheme is acquired at a relatively early stage, with children producing the morpheme at $90 \%$ accuracy in obligatory contexts by the age of 36 months, a study conducted by Johnson, de Villiers and Seymour (2005) and de Villiers and Johnson (2007) reveals that children use [-s] in both spontaneous and elicited production from the age of $3 ; 5$, but that they use it with difficulty until the age of five or six, claiming that production of the morpheme is ahead of comprehension.

This paper reports on a four-month longitudinal case study which looks at the use of the third-person singular (3SG) [-s] morpheme as it occurs in both obligatory and non-obligatory contexts in spontaneous speech produced by five language minority children studying in a primary school in Dublin, where the language of instruction is the subjects' Second Language (L2). For the purposes of this study, the term language minority children refers to the subjects in the context that the language they are speaking is a minority language in the setting of the study.

An error analysis is conducted on the data and each subject's level of mastery of the morpheme in terms of a percentage criterion is established. Errors arising from the overgeneration of be in a third person singular context are also analysed, and categorised according to their intended meaning of progressive, generic or stative. Results from the error analyses are then discussed in the context of a number of theories which have been put forward in the literature to account for the development of the 3SG. In addition, this study explores whether evidence can be found from the data to support the notion that the omission of the third person [-s] morpheme and the possessive [-s] 
morpheme happen at the same stage in the L2 acquisition process, as Radford and Galasso (1998) found in First Language (L1) acquisition. The issue of whether or not the sporadic omission of the two morphemes is related will also be investigated.

Research into the acquisition of the third person [-s] morpheme in L2 acquisition has mainly focused on this apparent optional use of the non-finite form of the verb in an obligatory finite context, with constructions such as he go occurring in the data, rather than the appropriate finite form he goes. The following literature review focuses on prominent studies in the area, which include Ionin and Wexler (2002), Meisel (1997), Prévost and White (2000), Wexler (1994, 1996), Theaksto, Lieven and Tamasello (2003), Legate and Yang (2007), Picon Jara (2015) and Rasanen, Ambridge and Pine (2014). These will be discussed in order to see if this study supports or challenges the relevant theories as they are discussed in the literature.

\section{Literature Review}

An explanation which has been put forward as to why children produce sentences with fewer inflected forms than adults is the Optional Infinitive (OI) hypotheses (see for example, Wexler, 1994; 1996; Legate and Yang, 2007). The OI hypothesis is a theory that refers to a stage in the early grammatical development of a language learner where both finite and non-finite forms are simultaneously produced in obligatory finite environments. The theory, which uses a Unique Checking Constraint (UCC) framework, attempts to provide a unified nativist account of children's knowledge of verb movement and verb inflection across languages (Croker, Pine and Gobet, 2000). The UCC, which governs the grammar of the child, results in errors in languages that require double-checking, such as obligatory subject languages like English, as the UCC prevents checking against two functional categories in child grammar, in this case Tense and Agreement. As explained by Kallulli and Tasmowski (2008, p. 349), the essential idea of the UCC is that whenever double-checking is required, children will fail to compute the derivation, and as the UCC applies to the grammar as a whole, it allows children to accept and produce ungrammatical constructions. As only one feature will be checked, either the feature of Tense and / or the feature of Agreement will be omitted. Thus, Tense and Agreement can be left underspecified. According to this model, language learners go through an initial stage in language acquisition - the optional infinitive stage - during which they lack the knowledge that tense and agreement marking is obligatory in finite clauses. Until this knowledge matures at a later stage in the acquisition process, they will continue to produce finite and non-finite forms where a finite form is obligatory in the adult language, and this alternating between finite and non-finite forms is the most fundamental property of the Optional Infinitive Hypotheses.

The theory can be used to explain and predict a number of phenomena occurring in the speech of learners acquiring English, such as the use of finite and non-finite verb forms in finite contexts, so that learners are likely to produce correct utterances such as he eats parallel to producing incorrect utterances such as he eat.

A further property associated with the OI stage is the use of the accusative case in place of the nominative pronoun (Prévost and White, 2000). This theory predicts that language learners might say he eat, he eats or him eat, but should never produce the accusative pronoun with a verb that is inflected with the third person singular morpheme, such as him eats.

The OI framework can also be used to explain why learners' utterances tend to agree in person and number with their subject when they use tensed forms, such that a language learner tends to say he goes rather I goes or you goes.

However, the OI hypothesis is not without criticism. Croker, Pine and Gobet (2000) and Freudenthal, Pine and Gobet (2005) point out that predictions made by the OI hypothesis are qualitative rather than quantitative; while it can predict the presence or absence of certain kinds of errors, it does not say anything about when, where or how likely it is for these errors to occur, with the gradual decline in OI errors explained by the notion of maturation. They offer an alternative computational explanation with the Model of Syntax Acquisition in Children (MOSAIC), suggesting that OI errors are truncated verb forms learned from compound-finite structures in the input (Freudenthal et al., 2006, 2007, 2009), and to explain the relative percentages of root infinitive forms across a number of languages on the basis of "no built-in knowledge of syntactic categories or rules" (Freundenthal et al., 2010, p. 647).

Rasenan et al. (2014, p. 758) point out that as the various models which have grown out of the OI hypotheses have been tested against a wider range of languages other than English, they struggle to explain the high rate of OI errors and the extended nature of the OI stage in English. They suggest some of the errors produced by English-speaking children reflect a process of defaulting to a high-frequency /phonologically simple form, but they note that this explanation should be seen as a complementary rather than a competing explanation of the OI phenomenon and suggest a need for a model that combines both factors (Rasenan et al., 2014, p. 775). 
In addition, based on evidence from their study of a Turkish boy learning English as a second language, Haznedar and Schwartz (1997) challenge the OI hypothesis, questioning whether children learning a second language do actually go through an OI stage in the same way as children learning a first language, citing little evidence of null-subject sentences, in addition to little evidence of the accusative case being used in place of the nominative pronouns. Indeed, Ionin and Wexler (2002) also argue that L2 learners do not go through the Optional Infinitive stage that L1 children commonly go through between 2-4 years of age. Similarly, Helland and Alvarez (2007), using results from a longitudinal study of five Spanish children learning English, show that child L2 English replicates to a certain extend the OI stage of child L1, but lacks the co-existence with finite-forms, and echo Haznedar and Schwartz (1997) in citing the Missing Inflection Hypothesis to explain this lack of alternating between finite and non-finite forms. Helland and Alvarez (2007) also point out that one of the fundamental tenets of the OI hypothesis is the assumption that the OI stage can only mature once past tense is acquired and understood, however, as Helland and Alvarez (2007) point out, as most children acquiring an L2 will have already developed a notion of tense in their first language, there is a fundamental difference in the starting point of the proposed L2 stage.

One of the properties associated with the OI stage in L1 acquisition is null subject use with either finites or non-finites (Prévost and White, 2000). Legate and Yang (2007) frame their explanation of null subject use with the Optional Infinitive in Legate and Yang's (2002) theory of language and language learning. Their Variational Language Model (2007) show that the large percentage of OI in English "correspond to the proportion of verbs in the adult input that they consider to either punish or reward a [+ Tense] language (Grinstead, 2016, p. 359).

\section{The Study}

\subsection{Methodology}

This longitudinal study adopts case study as a methodological approach. Due to issues relating to the alleged lack of generalisability of single-case studies because of the difficulty in distinguishing idiosyncratic behaviour from general behaviour (Larsen-Freeman and Long, 1991), this study consists of multiple cases, which chronologically map the language development of the five subjects. The orientation of the study is qualitative in approach. The research design in this study is data-driven, with patterns in the data being identified and analysed.

While this research is primarily concerned with the performance analysis on qualitative data, this is not to say that quantification will not have a role to play, as analysis of the data will take the form of quantification. However, this analysis will take the form of descriptive statistics (frequency counts and percentages), a term used by Lazaraton (1995), and will not be analysed statistically.

\subsection{Participants}

The criterion for sampling was identified as language minority children attending an Irish primary school who had a language other than English as their L1 and were aged between five and eight years of age. All subject characteristics were checked at the selection process to ensure that they matched the criterion and checked for group bias. Prior to their participation in the study, the purpose and aims of the study were explained to parents and written parental consent was obtained.

This study is based on a corpus of spontaneous speech produced over a four month period by the subjects. The language of instruction is the subjects' L2. The sample comprised of one girl and four boys. The first language spoken by the subjects is Arabic $(\mathrm{N}=2)$, Romanian $(\mathrm{N}=1)$, Hindi $(\mathrm{N}=1)$ and Latvian $(\mathrm{N}=1)$. Two of the subjects were born in Ireland, one subject arrived as a baby, one subject was a year old on arrival and another subject arrived at the age of three. Subjects who were born in Dublin or arrived in Dublin at a young age were exposed almost exclusively to their L1 prior to commencing primary school. With the exception of one subject, all parents have very limited proficiency in the English language. Basic demographic information about the children and their parents' level of English proficiency was obtained from school records and from teachers, who had regular contact with each parent. The two schools attended by the five subjects are designated as disadvantaged by the Department of Education and Science. All of the subjects' primary schooling has been in Ireland and all subjects receive ESL (English as a Second Language) support.

\subsection{Procedures}

Empirical material was gathered by means of the UNS (Unstructured Natural Communication) elicitation method. Samples of spontaneous speech data were recorded at 7-14 day intervals over a four month period. All sessions were conducted in a relaxed manner, to make the child feel at ease, and to elicit more natural samples of speech data. Interviews consisted of casual conversation about topics of interest to the subjects' daily lives, such as, birthday parties, pets and weekend activities with their families. Prior to each interview, students picked a favourite book or 
game from the school library and during the latter part of each session, students either recounted the stories from these books to the researcher or played a board game with the researcher. Interviews ranged from eight to fifty minutes in duration. The duration of each recording session increased as subjects became more comfortable and familiar with the researcher.

All speech is transcribed using F4 transcription software for Windows and coded for the use and accuracy of the morpheme using the CHAT format (Codes for the Human Analysis of Transcripts). This allows for a quantitative analysis to be performed on the transcripts of the language interactions produced by the subjects of the study. As the purpose of this research is to analyse the subjects' learning of morphological markings and identify any salient patterns, the transcripts are coded for morphological and syntactic features. This coding, which is conducted in accordance with CHAT conventions, enables the transcripts to be analysed by the CLAN (Computerised Language Analysis) programme. CHAT and CLAN are complementary computational tools within the CHILDES (Child Language Data Exchange System) database.

In order to determine if a particular grammatical morpheme had been mastered and to obtain the acquisition profile for the morpheme, the acquisition criterion was set at $80 \%$ accuracy in obligatory contexts across three consecutive testing sessions, and if, in a given session, a participant produced fewer than five obligatory contexts for a particular morpheme, the data from that session was omitted from analyses (Jia and Fuse, 2007: 1286).

In order to avoid the comparative fallacy theory (Bley-Vroman, 1983), analysis of the data is not restricted to comparison with target-language norms. Following Palotti (2007), the current study adopts three complementary sources of evidence which are invoked to claim that at least some uses of the grammatical morpheme are productive; the presence of morphological minimal pairs, the presence of creative constructions and a high level of lexical variety of the morpheme.

\section{Error Analysis}

All obligatory cases that required the third person [-s] morpheme were identified and extracted from the data using a combination of KWAL, FREQ and COMBO commands in the CLAN programme and the number of times the morpheme was supplied or omitted was calculated. A qualitative analysis was performed on extracted utterances, and errors were classified into the four categories as outlined below (1). In addition, morphological productivity was explored in the form of lexical productivity, using the FREQ command. The number of different lexical items that appeared in obligatory contexts and the number of different lexical items inflected with the 3SG [-s] morpheme were counted. In order to ascertain whether subjects dropped the third person [-s] when asking a question, all utterances that contained questions were also extracted from the data. Analysis did not include the irregular third person forms has and does.

(1)

1. Omission of the [-s] morpheme in an obligatory context

2. Inappropriate use of the $[-\mathrm{s}]$ morpheme

3. Overgeneration of auxiliary be with third person singular verb

4. Null subject sentence

Errors arising from the overgeneration of the verb be in a third person singular context (he is go in the garden) were marked as having generic, stative or progressive as their intended meaning. In addition, the use of the nominative subject he +bare stem, he +verb[-s], the non-nominative subject him + bare stem and he is/'s + bare stem were identified and extracted from the data for analyses. Cases excluded from analysis are outlined in (2).

1. Ambiguous forms (he's work in his car)

2. Lexical items that can function as a noun or a verb (drink and cake)

3. Utterances where the subject of the verb is not clear (every play car)

4. Zero-change verbs such as hurt, cut and let (because my tummy hurt)

5. Utterances where the succeeding lexical item commenced with /s/ (boys stays here)

To investigate whether the sporadic omission of the $3 \mathrm{SG}$ morpheme is related to the sporadic omission of the genitive [-s] morpheme, 93 obligatory contexts requiring the possessive [-s] morpheme were identified. As the number of possessive tokens in each cycle was low, it was not possible to work out a percentage accuracy figure for 
each cycle. However, an overall percentage accuracy figure was calculated based on the total number of tokens correctly inflected with the possessive morpheme for a particular subject.

\section{Results}

In total, 482 third person singular contexts were identified and extracted from a 1,021 minute corpus of spontaneous speech. Only one of the four subjects has mastered the morpheme. The remaining four subjects frequently use the non-finite form of the verb in an obligatory finite context. Two subjects use this non-finite in the majority of their productions in a third person context. Out of 482 third person singular contexts, there are 8 occasions where a finite form was incorrectly used and 238 occasions where non-finite verbs are incorrectly used.

Thirty eight cases of be + verb are observed, of which, 14 (37\%) have intended generic meaning, 22 (58\%) have intended stative meaning and $2(5 \%)$ have intended progressive meaning. For three subjects, the overgeneration of $b e$ is almost insignificant. However, for the other two subjects, the overgeneration of $b e$ in a third person singular context is a frequent occurrence in the first half of the study, after which it rarely, if ever, occurs.

Table 1. Occurrence in Obligatory Contexts

\begin{tabular}{lcc}
\hline Cycle & $\mathbf{3}^{\text {rd }}$ person singular [-s] & Genitive [-s] \\
\hline Subject 1 & $8 \%$ & $72 \%$ \\
Subject 2 & $17 \%$ & $27 \%$ \\
Subject 3 & $74 \%$ & $93 \%$ \\
\hline Subject 4 & $75 \%$ & $90 \%$ \\
Subject 5 & $94 \%$ & $100 \%$ \\
\hline
\end{tabular}

Table 1 shows the overall percentage accuracy of the total number of tokens correctly inflected with the 3SG morpheme compared with the corresponding figure for the genitive [-s] morpheme. There is a significant difference in the occurrence of the 3SG and genitive [-s] morpheme in Subject 1's data. Evidence from the remaining four subjects suggests that while the acquisition of the both morphemes occurs at a similar stage, the genitive marker is acquired slightly ahead of the 3 SG marker.

\section{Discussion}

Various theories have been put forward to account for the optionality in the use of 3SG inflectional morphology. This section discusses the present study's findings in terms of the above theories and looks at what implications this study has on current theoretical work.

\subsection{The Impaired Representation Hypothesis (IRH)}

The impairment approach argues that the optionality in production of tense and agreement morphemes is due to the functional categories of tense and agreement which are impaired or underspecified in L2 grammar (Meisel, 1997; Beck 1998; Eubank 1993 /1994 and Eubank et al., 1997). For the impairment explanation to hold true, L2 learners should create errors in their use of both finite and non-finite verbs, placing non-finite verbs in finite position, as well as finites in non-finite position. Observations from this study demonstrate that while the former is true, subjects rarely use a finite in a non-finite position, providing little support for the impairment approach. There are only 8 occasions out of a corpus of 482 third person singular contexts where a finite form is incorrectly used, however there are 238 occasions where non-finite verbs are used incorrectly.

\subsection{Missing Surface Inflection Hypothesis (MSIH)}

Prévost and White (2000) dismiss the notion that functional categories are impaired or missing in their discussions on the Missing Surface Inflectional Hypothesis (MSIH), an extension of Haznedar and Schwartz's (1997) Missing Inflection Hypothesis, and supported by Ionin and Wexler (2002) and Helland and Alvarez (2007). Although it makes the same predictions as the IRH with regard to non-finite verbs, albeit with different reasons, the two hypotheses differ as to their predictions regarding finite verb forms. The MSIH posits that finite forms are genuinely finite and should occur in finite position rather than non-finite position, while non-finite forms act as the default and sometimes occur as a substitute for inflection and sometimes are truly non-finite, resulting in their position varying between finite and non-finite. The IRH, on the other hand, posits that language learners produce non-finite forms in obligatory contexts as a result of the impairment in the feature-checking mechanism, the result being that non-finite forms can occur anywhere. 
Prévost and White (2000) and Lardiere (2000) argue that if functional categories or functional features are impaired in the L2, as implied by the impairment explanation, then there is nothing that would prevent the production of incorrect inflectional morphemes or the random use of finite and non-finite verbs in obligatory finite or non-finite contexts. They cite evidence that L2 learners frequently use non-finite verbs in finite context, but that they rarely place finite verbs in non-finite contexts. Prévost and White (2000) argue that there is no evidence of syntactic impairment in L2 grammar and that functional categories are indeed present. Instead, they put forward the notion of a mapping problem between abstract features and surface morphological forms that can account for the omission of agreement morphology in the acquisition of a second language, suggesting that the default non-finite form is produced in a finite context:

L2 learners have abstract features for finiteness and agreement in their interlanguage representation, as evidenced by the syntactic and morphological behaviour of finite verbs. They do, however, exhibit problems with the surface morphological realization of particular forms, sometimes resorting to default forms; there are in other words, ..........'mapping problems' between surface forms and abstract features.

Prévost and White (2000: 127)

This mapping problem, which is also supported by Lardiere (2000), is explained in terms of Distributed Morphology (DM), a framework of theories put forward by Halle and Marantz (1993), cited in Prévost and White (2000). DM posits that an inflected morpheme is associated with grammatical features such as tense, number, gender or person, and can be inserted into a host node in the syntax as long as its features are consistent with the features of the hosting node. While the features of the syntactic or hosting node will be fully specified, features of the lexical item that it will be hosting may be either partially specified or underspecified. It is not necessary for there to be an exact match between features of the host node and the features of the lexical item to be inserted, once the features of the lexical item are a subset of the host node, it is sufficient. If there is not an exact match, then there is competition between the various items for inflection, and the item which is the best possible match wins out and is inserted into wherever the syntax has determined it should go. Using DM, Prévost and White (2000) argue that L2 learners have acquired the relevant features of the terminal nodes in the syntax, by means of their L1, from Universal Grammar (UG) or from their L2 input, but that they have not fully acquired feature specifications of the associated lexical items. Therefore, non-finite verbs are underspecified for finiteness and consequently can be inserted into a node bearing the [+finite] feature. Finite verbs, on the other hand, are specified for finiteness [+finite], and therefore cannot be inserted into a non-finite node [-finite]. As non-finite verbs are underspecified, they function as defaults in L2 learning, and can be produced in either [-finite] or [+finite] contexts, thus explaining the occurrence of non-finite forms in obligatory finite contexts.

In order to investigate whether the MSIH could offer an explanation for the use of finites by the subjects in this study, following Ionin and Wexler (2002: 104), the following two hypotheses are explored:

Hypothesis 1: The L2 learners will produce non-finite forms in place of finite forms.

Hypothesis 2: Since the abstract categories and feature-checking mechanisms are in place for L2 learners, there will be little or no incorrect finiteness inflection in the speech of the L2 learners.

Table $2 . \%$ of cases where non-finite form occurred in obligatory finite context

Subject $\%$ of cases where non-finite form occurred in obligatory finite context

Subject $192 \%$

Subject $283 \%$

Subject $326 \%$

Subject $425 \%$

Subject $56 \%$

As is clear from Table 2, the first hypothesis was confirmed by observing the percentage of times that a non-finite form was found in an obligatory finite context. Omission of the morpheme was particularly high for Subject 1 and Subject 2, and relatively high for subject 3 and subject 4, providing evidence to support the first hypothesis.

The second hypothesis was confirmed with only eight incorrect cases of finite inflection out of a corpus of 482 third person singular contexts. In the current study, when subjects did use the [-s] morpheme, they used it in an 
appropriate context on $93 \%$ of occasions. This figure reflects results from previous studies which show that although children often omitted the third person [-s] morpheme, when they did produce it, it was used appropriately approximately 95\% of the time (Leonard, Miller and Owen, 2000; Prévost and White, 2000). Thus, while a language learner might produce the utterances she play or she plays, they are unlikely to produce you plays. This extremely low number of incorrect cases of finite use in the current data supports the second hypothesis, namely that there will be little or no incorrect finiteness inflection in the speech of L2 learner. This evidence also presents a challenge for the impairment approach, as if functional features were impaired or missing, then checking cannot take place and there would be no way to prevent agreement mismatches, therefore, a higher rate of incorrect use of the finite inflection would be expected. Thus, it can be said that in the L2 grammar, features and the feature checking mechanism that underlies verbal finiteness are fully in place, ensuring that finite verbs should only occur in finite position.

In addition, according to the MSIH, as features are assumed to be present in the initial period of language acquisition, it should not be the case that non-finite forms occur only in the early stages of the acquisition process and finite forms occur at a later stage in the acquisition process. Instead, Prévost and White (2000) state that L2 learners will continue to use non-finite forms even when they have acquired finite forms, and explain this by suggesting that, occasionally, access to the finite form is blocked as a result of communication or processing pressures. This is evident in this study, as one subject who has mastered the morpheme under criteria set by Jia and Fuse (2007) produces utterances where a non-finite is used in an obligatory finite context and also uses finite verbs in obligatory non-finite contexts .

\subsection{Constructivist, Input-Driven Approach}

An alternative explanation put forward posits that the use of non-finite forms in a finite context is a result of the occurrence of questions in their input (Croker et al., 2000; Theakston et al., 2003; Blom, Paradis and Sorenson Duncan, 2012). When questions are formulated, the subject, such as he, is immediately followed by a non-finite form, such as eat, resulting in the string he eat occurring in the language learner's input. This constructivist, input-based approach proposes that the optional use of the third person singular [-s] may reflect item-based learning and the patterns of verb use in the language to which children are exposed (Theakston et al., 2003). This approach is based on the fact that most of the error patterns predicted by the OI hypotheses can be found in the child's input, while forms predicted to be absent by the OI hypotheses are not found in the child's input. For example, the sequence he eat could appear in the child's input outside the matrix clause in the form of what will he eat while the sequence him goes will not be found in the input. Examples of such questions which are uttered by the investigator in this study are given in (3).

If children acquire language structures on an item-based approach, they will acquire different language patterns from declarative sentences and from questions. They would therefore acquire the string he eat from a question in their input, and likewise, acquire he eats from a declarative sentence. Consequently, they might produce both finite and non-finite forms in finite contexts, or as Theakston et al. (2003) point out, it could cause them to be confused as to whether or not the [-s] morpheme needs to be supplied at all. This approach would help predict what verbs are more likely to be inflected correctly with the third person singular marker, with children more likely to produce finite verbs in finite contexts if the particular verb appears modelled in a declarative statement rather than hearing it modelled in a question in their input.

Results from the study conducted by Theakston et al. (2003) show that verbs modelled in the input influence the likelihood that the language learner will produce appropriately inflected third person verbal forms in finite contexts with novel verbs. Although the present study does not contain novel verbs, it is still possible to see if verbs that are modelled in the input are likely to be produced in the appropriate finite context by the subjects in the study. Such a finding would provide support for a constructivist, input-driven approach. For this analysis, the data of the subject who has mastered the morpheme was excluded. The other four subjects were considered to exhibit some degree of optionality in the verbal inflection of the third person singular [-s] morpheme. There are five occasions in the study where input could have aided the learner's verbal inflections, an example of which is given in (3). There are three occasions in the study where the utterance contains a non-finite verb, following a question from the investigator, where the verb in the question is in non-finite form, an example of which is found in (4). However, there are nine cases in the study where the subject does not use the verbal inflection which was modelled in the preceding sentence. In (5), an example can be seen where the investigator asks a question, however, the subject answers the question using a form other than the form that has occurred in the preceding utterance. In (6), there is an example of where the verb appears in non-finite form in the investigator's question. However, the subject answers the question with the 
appropriate finite form, suggesting that the subjects can go beyond the input and produce verbs inflected with the [-s] morpheme, where the verb had been unmarked in the input. Although there are only 17 cases in the corpus where the input could have been used by the subject to aid in the verbal inflection process, this only happens on five occasions.

(3) Investigator: it's in your bed, he sleeps in your bed?

Subject 1: no, he sleeps his bed.

(4) Investigator: and when does your daddy use it?

Subject 1: ehm use it in his shop.

(5) Investigator: he eats all ten?

Subject 1: yeah, eat all, eat all his lunch like that.

(6) Investigator: what does he want?

Subject 2: he wants to eat.

\subsection{The Missing Agreement Account and the Implicit Rule Deficit Account}

The Missing Agreement Account (Clahsen, 1989) and the Implicit Rule Deficit Account (Gopnik \& Goad, 1997) are two models which have been put forward to account for the use of non-finite forms in obligatory finite contexts in language produced by language-impaired children. One assumption made by both of these models is that correct inflections are primarily the result of rote memorisation of inflected forms.

Clahsen and Hansen (1993) test two assumptions on the mechanism for correct production of finite verb forms, one being that language learners do not have a general paradigm for number and person inflection and the other being that finite verb forms are memorised on a verb-by-verb basis, with children learning inflected forms as separate lexical items, when the verbal inflections are initially emerging, but before they are acquired, as found by Theakston et al. (2003). Applying these assumptions, analysis of utterances produced by a language learner should yield two mutually exclusive verb lists, those correctly inflected in finite form and those that are only produced as non-finite verb forms.

To test this notion, following Miller and Leonard (1998), each verb that occurred at least twice in each subject's corpus was assigned to one of three categories: always correct, for verb types that are always correctly inflected; never correct, for verb forms that are never correctly inflected; and sometimes correct/ sometimes incorrect, for verb forms that are produced at least once without inflection and once with inflection. If language learners tended to learn inflected words as unanalysed lexical items, it would be expected that no verb would be assigned to the sometimes correct / sometimes incorrect category. Results from this study show each subject had lexical items in the sometimes correct / sometimes incorrect category, posing challenges for both the Missing Agreement Account and the Implicit Rule Deficit Account. Four of the five subjects display a higher number of verbs assigned to this sometimes correct / sometimes incorrect class. It is worth noting that items that are assigned to this category cluster together at a particular stage in the longitudinal study, depending on the particular stage in the acquisition process they are at.

Memory retrieval failure might account for inflected verbal forms that have been memorised being produced without the necessary inflection (Marcus et al., 1992). However, such retrieval errors would only account for $4.2 \%$ of occasions where the necessary past-tense inflection was not produced (Marcus et al., 1992). Miller and Leonard (1998) put this figure at $10.5 \%$ for the third person singular inflection. Retrieval errors for this morpheme would result in the production of the non-finite form of the verb in an obligatory finite context. Based on Miller and Leonard's figure of $10.5 \%$, retrieval errors might be able to explain the number of lexical items assigned to the sometimes correct category for two of the subjects in this study, with the sometimes correct category equivalent to $7 \%$ and $9 \%$ for these two subjects. The number of lexical items assigned to the sometimes correct category for the other three subjects are $16 \%$ for two subjects and $23 \%$ for one subject These figures are too high to be explained by memory retrieval failure. For the relevant three cycles in subject 5's data, 14\%, $21 \%$ and $14 \%$ of items are assigned to the sometimes correct category. For subject 2, the figures are $10 \%, 25 \%$ and $13 \%$. There is only one cycle in subject 3's data that had a sometimes correct category, and this figure is $23 \%$. Therefore, as all five subjects have lexical items in this category, and as memory retrieval failure cannot explain the errors in three of the five subjects, it can therefore be concluded that evidence from this study does not support the Missing Agreement Account and the Implicit Rule Deficit Account. 


\subsection{Overgeneration of be Forms}

Finally, there is one further structure which features in the data, and is particularly prominent in the data of two subjects which deserves a mention, and that is the use of phrases such as he's come and the sun is help Superman to get powers. Studies on the speech produced by children learning English as an L2 conducted by Ionin and Wexler (2002) made similar observations that their subjects produced the construction be + bare V in utterances such as I'm read or I'm buy beanie baby. This construction is used with a wide range of meanings, and is often used in utterances that contain an uninflected verb in place of a progressive participle, as in is come, is go, and initially, it might appear as if the overgeneration of $b e$ is used by the $\mathrm{L} 2$ learners in this study to express the progressive aspect. However, the vast majority of this type of utterance is used, not to express the progressive meaning, which only accounts for 5\% of cases, but used with intended stative meaning (58\%), followed by intended generic meaning (37\%).

\subsection{Genitive [-s] and 3SG [-s] Morphemes}

Radford and Galasso (1998) and Radford (1999) suggest a potential parallel between children's sporadic omission of the third person singular morpheme and their omission of the possessive [-s] marker, with both morphemes emerging at a similar stage in L1 acquisition. Other researchers who have made a link between the genitive and third person singular [-s] are Kayne (1993) and Berstein and Tortora (2005).

Table 1 shows the relative frequency of use of both morphemes for each subject in the current study. There is a significant difference in the occurrence of the third person [-s] morpheme and the possessive [-s] morpheme for one of the subjects in the study, challenging Radford and Galasso's (1998) L1 findings. Evidence from the remaining four subjects would suggest that while the acquisition of both morphemes occur at a similar stage, the possessive [-s] is acquired slightly ahead of the third person [-s]. The results from this study also reflect findings made by $\mathrm{Di}$ Domenica and Bennati (2007) when they observed that the genitive [-s] morpheme is present in a high percentage of cases where the third person singular $[-\mathrm{s}]$ is missing. The data for the remaining four subjects suggests a potential parallel between the acquisition of the two morphemes. Radford and Galasso (1998) draw on the syntactic parallels and the morphological similarities between the two morphemes to explain this, describing the acquisition of the genitive possessive [-s] and the third person singular [-s] as a three stage process. In the first stage, agreement is not marked and subjects and possessors carry default objective marking, with the necessary [-s] morphemes omitted, resulting in such utterances as him eat and him hand. They explain the default objective marking by suggesting that the genitive case of possessive constructions and the nominative case of verbal constructions are checked with a nominal and verbal inflectional head respectively, with the objective case acting as the default in structures that lack agreement. The shift from objective possessors to genitive possessors and the shift from objective subjects to nominative subjects reflects a parallel change from a subject underspecified for subject / possessor agreement, to a structure fully specified for agreement features. In the second stage, there is optional agreement marking. If agreement is marked, subjects will carry nominative case and verbs will be inflected with the [-s] morpheme in the case of third person singular verbal constructions. If agreement is not marked, utterances that occur in the initial stage will be produced. Likewise, for utterances containing possessive constructions, if agreement is marked, possessors will be marked with the genitive case and carry the possessive [-s] inflection. Otherwise, initial stage utterances will be produced. In the third and final stage in the acquisition process, agreement will be marked and verbal constructions will carry nominative case and the verb will be inflected with the third person [-s] morpheme and possessive constructions will carry genitive case and the necessary [-s] possessive inflection.

One view that Radford and Galasso (1998) pursue is the notion that possessors in nominal / pronominal clauses and subjects in verbal clauses show a similar pattern of development. Data from two of the five subjects in this study challenge this notion. Analysis of one subject's data reveals there is only one utterance where the pronominal possessor is marked by the objective case, with no instance of the third person singular marked by the objective. Data from the other subject shows the use of the objective case him in both third person singular verbal constructions and possessive structures. However, while $22 \%$ of utterances produced by this subject with third person singular subjects have objective him subjects, a staggering $99 \%$ of pronominal possessive structures take the objective him possessor in the form of him + noun. Only $1 \%$ has a genitive his possessor. These figures do not reflect the L1 findings of Radford and Galasso (1998), where the figures are virtually identical, at 78\% and $77 \%$ respectively. From cycle four, this subject makes the shift from objective subjects to nominative subjects in third person singular verbal utterances, however, a similar shift is not evident in the case of possessive, with objective possessors dominating throughout the whole study. It can be concluded from this subject's data that possessors and subjects do not show a similar pattern of development, presenting a challenge for Radford and Galasso's notion. 
Findings from this subject's data are consistent with the view expressed by Galasso (2004), following Kayne (1993), who grants the possessive [-s] structure the status of a possessor-agreement inflection, just as a verbal inflection has the status of subject-verb agreement inflection. He explains that at an early stage of syntactic development, the head of INFL goes unspecified for both nominal (genitive) and verbal (subject) INFL heads. However, this is only the case in the first four recording cycles of this subject's data. Thereafter, verbal projections appear to be fully specified, while possessive projections still remain underspecified for the remainder of the study. As the remaining three subjects in the study are considered to have acquired the morpheme, their data is not analysed.

\section{Conclusion}

Evidence from the current study was used to see if the data supported or challenged the different theories that have been put forward in the literature to account for the parallel use of both finite and non-finite verb forms in obligatory finite contexts. Results from this study present a challenge for the impairment approach, constructivist input driven approach, the Missing Agreement Account and the Implicit Rule Deficit Account. This leaves the OI hypothesis and the MSIH. Evidence from this study can be used to support some of the predictions made by the OI theory. These include the parallel production of both non-finite and finite forms in obligatory finite contexts, the occurrence of an accusative pronoun with a non-finite verb, but never with a finite verb, agreement in person and number with the subject of the verb in a tense form, and few commission errors. However, there are properties of the OI theory that are not found in the present study, slightly weakening the support for the theory. Such properties include the lack of evidence from four of the five subjects of non-nominative case use, and the small amount of evidence of the null subject use with either finites or non-finites. The two hypotheses tested under the MSIH, namely the production of non-finite forms in place of finites and the absence or low occurrence of incorrect finiteness, would argue in favour of the MSIH, with incorrect finite errors accounting for only 3\% of errors. This is in addition to the large body of evidence of where subjects used non-finite forms in place of finite forms and evidence that non-finite verbs do not only occur in finite position in the early stages of language acquisition and, similarly, that finite forms do not occur only at a later stage in the acquisition process.

Finally, the paper looked at the acquisition trajectory for the possessive [-s] genitive marker and investigated claims made in the literature that there is a potential parallel between the omission of the possessive [-s] marker and the omission of the third person [-s] morpheme. Investigating the occurrence of each morpheme in an appropriate context reveals that, for four of the five subjects, there does appear to be some similarity between the acquisition of both morphemes, with the acquisition of the genitive [-s] morpheme occurring slightly earlier than the third person [-s] morpheme. However, data from one subject would challenge this notion of similarity, by showing significant differences between the number of possessive morphemes supplied in obligatory contexts $(8 \%)$ and the number of third person [-s] morphemes supplied in obligatory contexts (72\%). That the objective case is the default case in both nominal possessive projections and third person verbal projections has also been put forward in the literature. While there is evidence that the objective is the default case applied for both verbal and nominal projections in one subject's data, objective case marking on verbal projections ceases in cycle four of the data, but remains a feature of nominal projections for the duration of the study, questioning the extent to which a parallel occurs between possessive and third person [-s] inflections.

\section{References}

Beck, M. L. (1998). L2 acquisition and obligatory head movement: English-speaking learners of German and the local impairment hypothesis. Studies in Second Language Acquisition, 20, 311-348. https://doi.org/10.1017/s0272263198003027

Bernstein, J. \& Tortora, C. (2005). Two type of possessive forms in English. Lingua, 115, 1221-1242. https://doi.org/10.1016/j.lingua.2004.03.002

Bley-Vroman, R. (1983). The comparative fallacy in interlanguage studies: The case of systematicity. Language Learning, 33, 1-17. https://doi.org/10.1111/j.1467-1770.1983.tb00983.x

Blom, E., Paradis, J. \& Sorenson Duncan, T. (2012). Effects of Input Properties, Vocabulary Size, and L1 on the Development of Third Person Singular $-\mathrm{s}$ in Child L2 English. Language Learning, 62(3), 965-994. https://doi.org/10.1111/j.1467-9922.2012.00715.x

Bobaljik, J. (2001) Realizing inflection: Why morphology does not drive syntax. Unpublished manuscript, University of McGill.

Brown, R. (1973) A First Language. Cambridge, MA: Harvard University Press. https://doi.org/10.4159/harvard.9780674732469 
Clahsen, H. (1989). The grammatical characterisation of developmental dysphasia. Linguistics, 27, 897-220. https://doi.org/10.1515/ling.1989.27.5.897

Clahsen, H. \& Hansen, D. (1993). "The Missing Agreement account of specific language impairment: Evidence from therapy experiments". Essex Research Reports in Linguistics, 2: 1-37.

Croker, S., Pine, J. \& Gobet, F. (2000). Modelling Optional Infinitive Phenomena. Proceedings of the $3^{\text {rd }}$ International Conference on Cognitive Modelling: 78-85.

De Villiers, J., and de Villiers, P. (1973) A Cross-Sectional Study of the Acquisition of Grammatical Morphemes in Child Speech. Journal of Psycholinguistic Research, 2, 267-278. https://doi.org/10.1007/BF01067106

De Villiers, J. \& Johnson, V. (2007) The information in third person /s/: acquisition across dialects of American English. Journal of Child Language, 34, 133-158. https://doi.org/10.1017/S0305000906007768

Di Domenica, E. and E. Bennati 2007. "The acquisition of English 's genitive constructions by native speakers of Italian: some experimental data compared to teaching materials". Proceedings of the Ming Chuan University Conference Integrating English Teaching and Applied Linguistics Taiwan.

Enç, M. (1990) On the absence of the present tense morpheme in English. Unpublished manuscript, University of Wisconsin, Madison.

Eubank, L. (1993/1994). On the transfer of parametric values in L2 development. Language Acquisition 3, 183-208. https://doi.org/10.1207/s15327817la0303_1

Eubank, L., Bischof, J., Huffstutler, A., Leek, P. \& West, C. (1997). 'Tom eats slowly cooked eggs': thematic-verb raising in L2 knowledge. Language Acquisition, 6, 171-199. https://doi.org/10.1207/s15327817la0603_1

Freudenthal, D., Pine, J. \& Gobet. F. (2005) Simulating the Cross-Linguistic Development of Optional Infinitive Errors in MOSAIC. Proceedings of the $27^{\text {th }}$ Annual Meeting of the Cognitive Science Society.

Freudenthal, D., Pine, J. \& Gobet. F. (2006) Modeling the development of children's use of Optional Infinitives in Dutch and English using MOSAIC, Cognitive Science, 30(2), 277-310. https://doi.org/10.1207/s15516709cog0000_47

Freudenthal, D., Pine, J. \& Gobet. F. (2007) Modeling the development patterning of finiteness marking in English, Dutch, German, and Spanish using MOSAIC, Cognitive Science, 31(2), 311-31.

Freudenthal, D., Pine, J. \& Gobet. F. (2009) Simulating the referential properties of Dutch, German, and English root infinitives in MOSAIC, Language Learning and Development, 5(1), 1-29. https://doi.org/10.1080/15475440802502437

Freudenthal, D., Pine, J. \& Gobet. F. (2010) Explaining quantitative variation in the rate of Optional Infinitive errors across languages: a comparison of MOSAIC and the Variational Learning Model, Journal of Child Language, 37(3), 643-669. https://doi.org/10.1017/S03050009090523

Galasso, J. (2004). The acquisition of inflection and the Dual Mechanism Model: a case study. Proceedings of the Child Language Research Forum 2004, Stanford: 98-107.

Gopnik, M. \& Goad, H. (1997). What underlies inflectional error patterns in genetic dysphasia? Journal of Neurolinguistics, 10, 109-137. https://doi.org/10.1016/S0911-6044(97)00003-1

Grinstead, J. (2016). Root Infinitives in Child Language and the Structure of the Clause. In J. Lidz, W. Snyder \& J. Pater (Eds.), The Oxford Handbook of Developmental Linguistics (pp. 341-366). Oxford: Oxford University Press. https://doi.org/10.1093/oxfordhb/9780199601264.013.15

Halle, M. \& Marantz, A. (1993). Distributed morphology and the pieces of inflection. In K. Hale \& S. J. Keyser (Eds.), The view from Building 20: Essays in linguistics in honor of Sylvain Bromberger (pp. 111-176). Cambridge, MA: MIT Press.

Hawkins, R. (2007). Emergent and innate sources of knowledge in the early L2 acquisition of English verbal morphology. Essex Research Reports in Linguistics Vol. 53.

Haznedar, B. \& Schwartz, B. D. (1997). Are there optional infinitives in child L2 acquisition? In E. Hughes, M. Hughes \& A. Greenhill (Eds.), Proceedings of the $21^{\text {st }}$ Annual Boston University Conference on Language Development (pp. 257-268). Somerville, MA: Cascadilla Press. 
Helland, C. \& Alvarez, E. (2007). The optional infinitive stage and child L2 English. Bells: Barcelona English Language and Literature Studies Vol. 16.

Ionin, T. \& Wexler, K. (2002). Why is 'is' easier than '-s'? acquisition of tense / agreement morphology by child second language learners of English. Second Language Research, 18(2), 95-136. https://doi.org/10.1191/0267658302sr195oa

Johnson, V., de Villiers, J., and Seymour, H. (2005) Agreement without understanding? The case of third person singular /s/. First Language, 25 (3), 317-330. https://doi.org/10.1177/0142723705053120

Jia, G. \& Fuse, A. (2007). Acquisition of English grammatical morphology by native Mandarin-speaking children and adolescents: age-related differences. Journal of Speech, Language, and Hearing Research, 50, 1280-1299. https://dx.doi.org/10.1044/1092-4388(2007/090)

Kallulli, D. \& Tasmowski, L. (2008). Clitic Doubling in Baltic Languages. Volume 130 of Linguistik Aktuell / Linguistics Today. John Benjamins Publishing Company. https://doi.org/10.1075/la.130

Kayne, R.S. (1993). Toward a modular theory of auxiliary selection. Studia Linguistica, 47(1), 3-31. https://doi.org/10.1111/j.1467-9582.1993.tb00837.x

Lardiere, D. (2000). Mapping features to forms in second language acquisition. In J. Archibald (Ed.), Second language acquisition and linguistic theory (pp. 102-129). Oxford, Blackwell.

Larsen - Freeman, D. E., \& Long, M. H. (1991). An Introduction to Second Language Acquisition Research. New York: Longman.

Lazaraton, A. (1995). Qualitative Research in Applied Linguistics: A Progress Report. TESOL Quarterly, 29(3), 455-472. https://doi.org/10.2307/3588071

Legate, J. A. \& Yang, C. (2007). Morphosyntactic Learning and the Development of Tense. Language Acquisition, 14(3), 315-344. https://doi.org/10.1080/10489220701471081

Legate, J. A. \& Yang, C. (2002). Empirical Reassessment of the Poverty Stimulus Argument, Linguistic Review, 19, 151-162. https://doi.org/10.1515/tlir.19.1-2.151

Leonard, L., Miller, C. \& Owen, A. (2000). The comprehension of verb agreement morphology by English-speaking children with specific language impairment. Clinical Linguistics \& Phonetics, 14 (6), 465-481. https://doi.org/10.1080/026992000415886

Marcus, G., Pinker, S., Ullman, M., Hollander, T. Rosen \& Xu, F. (1992). Overregularisation in Language Acquisition. Monographs of the Society for Research in Child Development, Serial No. 228, 57(4). https://doi.org/10.2307/1166115

Meisel, J. (1997). The acquisition of the syntax of negation in French and German: contrasting first and second language development. Second Language Research, 13, 227-263. https://doi.org/10.1191/026765897666180760

Miller, C. \& Leonard, L. (1998). Deficits in finite verb morphology: some assumptions in recent accounts of specific language impairment. Journal of Speech, Language, and Hearing Research, 41, 1432-1443. https://doi.org/10.1044/jslhr.4103.701

Palotti, G. (2007). An operational Definition of the Emergence Criterion. Applied Linguistics, 28, 361-382. https://doi.org/10.1093/applin/amm018

Picon Jara, L. (2015). The Acquisition of the $3^{\text {rd }}$ person singular $-s$ in English: Exploring its use by L2 Learners of English in written oral register. Universitat Autonoma de Barcelona. Retrieved from https://ddd.uab.cat/pub/tfg/2015/137841/TFG_laurapicon.pdf

Prévost, P. \& White, L. (2000). Missing surface inflection or impairment in second language acquisition? Evidence from tense and agreement. Second Language Research, 16, 103-133. https://doi.org/10.1191/026765800677556046

Radford, A. (1999). Children's possessive Structures. Essex Research Reports in Linguistics, Volume 19.

Radford, A. \& Galasso, J. (1998). Children's possessive structures: a case study. Essex Research Reports in Linguistics, $19,37-45$. 
Rasanen, S., Ambridge, B. \& Pine, J. (2014). Infinitives or Bare Stems? Are English-speaking children defaulting to the highest-frequency form? Journal of Child Language, 41, 756-779. https://doi.org/10.1017/S0305000913000159

Sauerland, U. (2002) The present tense is vacuous. Snippets, 6, 12-13.

Theakston, A., Lieven, E. \& Tomasello, M. (2003). The role of the input in the acquisition of third person singular verbs in English. Journal of Speech, Language, and Hearing Research, 46, 863-877. https://doi.org/10.1044/1092-4388(2003/067)

Wexler, K. (1996). The development of inflection in a biologically based theory of language acquisition. In M. L. Rice (Ed.) Toward a genetics of language (pp. 113-144). Mahwah, NJ: Erlbaum.

Wexler, K. (1994). Optional Infinitives, head movement and the economy of derivations. In D. Lightfoot \& N. Hornstein (Eds.) Verb movement (pp. 305-350). Cambridge, UK: Cambridge University Press. https://doi.org/10.1017/CBO9780511627705.016 